\title{
TRANSPOSICIONES METAFÓRICAS EN LA TERMINOLOGÍA MÉDICA ESPAÑOLA
}

Resumen. En el estudio se contemplan las peculiaridades de las metáforas lexicalizadas propias del ámbito terminológico de medicina. Aparte de señalar la especificidad del proceso de lexicalización que caracteriza los términos especializados, se comentan también los valores semánticos y pragmáticos de las transposiciones metafóricas en la terminología médica. En el análisis caben, de igual modo, los epónimos y los dobletes terminológicos.

Palabras clave: metáforas lexicalizadas, lenguajes de especialidad, terminología médica, epónimos, dobletes terminológicos.

\section{Neología de sentido dentro del ámbito terminológico}

La creación de términos científicos cuenta con diferentes procedimientos formativos que corresponden a tres mecanismos básicos, a saber, la neología formal (creación de una palabra nueva), la neología sintáctica (cambio de categoría gramatical) y la neología de sentido (atribución de un sentido nuevo a una palabra ya existente). En este estudio nos centraremos en la última de las modalidades delimitadas, prestando una atención especial a las formaciones neológicas de carácter metafórico presentes en el ámbito terminológico de la medicina ${ }^{1}$.

* Uniwersytet Łódzki.

${ }^{1}$ Se supone que la terminología médica constituye uno de los léxicos de especialidad más ricos y más extensos del español. Según Burgos Cuadrillero y Rohr Schrade (2016: 77-78), la terminología médica comprende alrededor de 500.000 términos, de los cuales aproximadamente 20.000 hacen referencia a funciones orgánicas y en torno a 60.000 a enfermedades y medios de investigación. Se trata de una terminología plagada de helenismos y latinismos, lenguas que durante siglos constituían un medio de comunicación en el ámbito de la medicina. 
Suele admitirse que los así llamados lenguajes especializados asignan a los conceptos unas denominaciones nuevas, específicas. Deberíamos ser conscientes de que, en realidad, la creación de palabras nuevas en el sentido más estricto, es decir, la formación de lexemas que no se base en elementos lingüísticos ya existentes, constituye una excepción. Las lenguas, entre ellas también las lenguas de especialidad, han de remitirse constantemente a unidades preexistentes, lo cual, en el ámbito especializado, conduce al proceso de terminologización. Se trata de un procedimiento formativo mediante el que la palabra adopta sobre su valor semántico primitivo otro significado específico que corresponde a un determinado campo de saber. Convendría apuntar de inmediato que algunos investigadores, entre ellos, Cabré (1993: 190), en lugar de adopción de un nuevo valor de significado, prefieren hablar de la modificación del significado de una unidad, la cual desemboca en la creación de una nueva unidad. Los procedimientos que hacen posible dicha creación consisten fundamentalmente en la ampliación, la restricción o en el cambio del significado de la forma de base.

De un modo bastante estereotipado, la terminologización suele ejemplificarse con cambios de significado basados en el reconocimiento de similitudes que conducen a un uso metafórico de una palabra del lenguaje común dentro del lenguaje especializado. Obviamente, se trata de una visión simplificada del fenómeno puesto que la direccionalidad «lengua común $\rightarrow$ lenguaje especializado» no es la única que se puede observar en el campo de la neología de sentido. En numerosas ocasiones, el paso de una palabra de una ciencia a otra se presenta como una vía de formación de términos muy productiva; Gutiérrez Rodilla (1998: 145) menciona, de igual modo, la posibilidad de recuperar una palabra del fondo antiguo de la lengua, ya desusada, e incorporarla al nuevo significado. Otra de las cuestiones que se debate al considerar el tema de la terminologización es la vinculada con el carácter de la analogía que constituiría el fundamento del proceso de adscripción de un nuevo significado. En varios planteamientos suele limitarse el problema de analogía al parecido físico que se traduce principalmente por similitudes de forma, función o posición. Resulta comprensible que el hecho de apoyarse en el parecido físico, ante todo desde una perspectiva cognitiva, se presenta como natural, concordando, además, con la actitud humana de partir de lo bien conocido y comparar con ello lo nuevo. No podemos olvidar, no obstante, que las analogías registradas en diferentes ámbitos terminológicos no descansan únicamente en un parecido puramente físico. Las semejanzas (de forma o función) fáciles de detectar coexisten con aquellas cuya motivación no se presenta como objetiva. Es el caso 
de muchas nociones abstractas cuya decodificación requiere un análisis sémico más matizado ${ }^{2}$.

Al considerar la neología de sentido como uno de los medio de denominación propios del ámbito de los lenguajes especializados cabe precisar que no todas las ramas de la ciencia recurren a este procedimiento con la misma frecuencia (así, supuestamente las ciencias exactas se decantan más bien por la derivación o la composición, mientras que las disciplinas sociales optan más a menudo por la neología de sentido). De acuerdo con la denominada fase preterminológica ${ }^{3}$, los tecnicismos creados en los primeros momentos de un área de conocimiento suelen tener más origen en la neología de sentido que en la neología de forma (hoy, por ejemplo, la neología de sentido parece prevalecer claramente en la genética).

\section{Metaforización terminológica}

La presencia de la metáfora en la ciencia no sorprende: los componentes de índole asociativa o las imágenes conceptuales no quedan al margen de la actividad mental común a cualquier tipo de pensamiento y no resultan nada ajenos a su formulación. Según Holton (1993: 29-57), en su labor científica, los investigadores recurren a tres modalidades de imaginación: la imaginación visual (que permite la formación de imágenes mentales satisfactorias a partir de imágenes ópticamente esquivas), la imaginación temática (que consiste en la práctica de dejar que los presupuestos del científico actúen durante un tiempo como guía de su propia investigación cunado todavía no hay pruebas suficientes de los presupuestos definidos) y la imaginación metafórica (que se basaría fundamentalmente en la captación de analogías). Las conceptualizaciones de naturaleza metafórica encuentran a menudo reflejo en el discurso científico ${ }^{4}$, no solamente de

${ }^{2}$ Consideren, por ejemplo, los nombres de estrategias comerciales tipo defensa comecocos o paracaídas dorado.

3 Para más detalle acerca de las peculiaridades de la llamada fase preterminológica véase Baran (2002).

${ }^{4}$ Piensen, por ejemplo, en la formulación bizcocho de pasas que se refiere a la expansión cosmológica (igual que la expansión cosmológica que, activando fuerzas mayores, no provoca desplazamientos [al menos en la escala planetaria], las pasas distribuidas sobre la superficie de un bizcocho que se cocina en un horno mantienen su tamaño aunque la masa se expande al calentar). De igual modo, en los discursos propios de las teorías sociológicas se recurre a menudo a una visión orgánica (y al mismo tiempo metafórica) de los hechos de sociedad. 
carácter divulgativo. En el marco del presente estudio nos limitaremos, sin embargo, a un tipo peculiar de metáforas, a saber, las metáforas lexicalizadas propias del ámbito terminológico.

La metaforización de índole terminológica, tal y como la concebimos nosotros, siguiendo, entre otros, a Kocourek (1994/1995) o Kacprzak (2000), conduce a la formación de un subtipo peculiar de metáforas lexicalizadas que deben contemplarse siempre en el marco de una definición especializada. Si la lexicalización del significado metafórico de una unidad léxica encuentra su fundamento en el criterio de frecuencia de uso (las metáforas originariamente vivas [estilísticas] se convierten gradualmente en elementos de sistema), la lexicalización propia del ámbito terminológico no depende de dicho criterio. La unida léxica de un determinado campo de partida (source-word en la terminología anglosajona), metafóricamente motivada, alcanza el estatus de término científico por vía de una definición especializada. En este sentido, las metáforas terminológicas no dependen del contexto, refiriéndose a los conceptos genéricos y no a los objetos individuales. De este modo, se asegura una codificación que traspasa la codificación habitual propia del ámbito de la lengua general, garantizando al mismo tiempo la validez de una de las características sobresalientes de términos, a saber, la univocidad. Por consiguiente, no consideramos como metáforas terminológicas lexicalizadas aquellas creaciones metafóricas que no han alcanzado el estatus de término y que no se registran en los diccionarios o glosarios especializados. Tampoco lo son para nosotros metáforas casuales que se manifiestan en la producción discursiva propia del ámbito científico.

\section{Términos de origen metafórico en la terminología médica española}

Nos parece interesante comprobar de qué manera podrían clasificarse e interpretarse las metáforas terminológicas procedentes del campo de la medicina. En el análisis emprendido hemos recurrido a varios diccionarios de medicina, tanto generales como propios de especialidades específicas (todos ellos figuran en la bibliografía final). En el primer acercamiento, que será de orden semántico, proponemos agrupar las metáforas recopiladas en tres grupos principales, teniendo en cuenta:

1) la clase semántica a la que pertenece el término metafóricamente motivado, 
2) el significado de la palabra base, $y$

3) el tipo de motivación.

Así pues, en la terminología médica española, según la clase semántica del término (1), pueden distinguirse ${ }^{5}$ :

- nombres de órganos y partes del cuerpo: acueducto, anillo, arco (de la aorta), bóveda (craneal), cáliz, caverna, concha, cripta, cuerda espinal, fosa (cerebral, prevesical), garganta del pie, intestino ciego, laguna (área, cerebral), silla turca, trompa (auditiva), túnica vaginal, vena (emisaria, estrellada, satélite)...;

- nombres de formaciones anatómicas: tejido, tela...;

- nombres de enfermedades: enfermedad danzante, elefancía, mal ardiente, parálisis agitante, tuberculosis cerrada, viruela loca...;

- nombres de síntomas: corazón péndulo, dedo en palillo de tambor, fiebre larvada, lengua de ciervo, pulso paradójico, pulso saltón, ruido de tempestad, verruga fugaz, vientre de tambor...;

- nombres de síndromes: síndrome de las lágrimas de cocodrilo de Kamiński, sindrome de plegaria mahometana, síndrome de las piernas inquietas...;

- nombres de neo- y malformaciones: boca de lobo, cresta de gallo, perla epidérmica, vesícula de porcelana...;

- nombres de deformaciones: estómago de reloj de arena, labio de tapir, mano apostólica, nariz en martillo, pierna de cigüeña, verga palmeada...;

- nombres de funciones de organismo: murmullo respiratorio, onda pulsátil, pulso lleno, soplo...;

- nombres de lesiones: fractura en bayoneta, fractura en pico de flauta, fractura estrellada...;

- nombres de exámenes, técnicas y operaciones médicas: amputación en guillotina, fenestración, incisión en bastón de hockey, injerto en acordeón, parto vicioso, percusión de piano, sutura en bolsa de tabaco...;

- nombres de instrumentos y materiales médicos: bomba (dental, estomacal), candelilla armada, compresa en cruz de Malta, trompetilla...

Según el significado de la palabra de base (2), pueden distinguirse grupos que se originan en los nombres de:

- animales: araña vascular, cuello de búfalo, ojo de liebre, ratón articular, úlcera en cresta de gallo...;

- plantas, frutas [reino vegetal]: cálices, células de avena, lengua afresada, mal de rosa, pera de goma, pulpa...;

${ }^{5}$ Una parte de los ejemplos que reunimos en nuestro estudio se halla igualmente en la monografía que publicamos en el año 2003. El trabajo al que nos referimos es fruto de una tesis doctoral dirigida por el Profesor Wiaczesław Nowikow, a quien reiteramos nuestro sincero agradecimiento por el apoyo brindado en aquella etapa de nuestra carrera académica. 
- objetos de distinta clase: abdomen en tablero de damas, anestesia en guante, lengua en rallador de queso, ruido de olla cascada, uña en cuchara, vientre en alforja...;

- materias, sustancias, alimentos: corazón de pan y manteca, lengua de madera, orina de Coca-Cola, ruido de pergamino, tumefacción vítrea, vientre de gelatina...;

- colores: angina blanca, atrofia roja, día verde, mal azul, muerte negra, roséola púdica...;

- profesiones o funciones desempeñadas: célula basurera, codo de los mineros, piel de marinero, tórax de zapatero...;

- personajes míticos, históricos, legendarios o literarios: edipismo, feto arlequín, mal de San Juan, pecho de amazona, pierna de polichinela...;

- relaciones de parentesco: célula madre, célula hija, piamadre...;

- cuerpos astrales: célula estrellada, mal lunar...;

- elementos de armamento: pulso en bala de cañón...;

- construcciones y sus elementos: laberinto (óseo), puente, tunelización, vestíbulo (de la aorta, del oído, de la vagina...);

- realidades geográficas y meteorológicas: enfermedad de Chicago, fiebre de las montañas rocosas, islotes de Langerhans, monte de Venus, región (olfatoria), sudor inglés...;

- realidades biológicas (incluidas partes del cuerpo y lo orgánico): cola (del páncreas), feto parásito, hígado de buey...;

- nociones de índole abstractas (o las arraigadas en la realidad sociohistórica o psicológica): monotonía cardíaca, silencio abdominal...;

- nombres de rasgos, cualidades (normalmente aplicados a los humanos): célula durmiente, diabetes frustrada, músculo antagonista, tumor benigno, viruela discreta....

Los rasgos semánticos que se muestran decisivos para la transposición de naturaleza metafórica (3) evocan más a menudo:

- forma: árbol (alveolar), dedos de araña, cordón espermático, cornete acústico, hueso turbinado...;

- función: atrio (de la laringe), túnica (muscular, vaginal), vena emisaria, ventilación pulmonar, vía...;

- movimiento: absceso errante, danza del testículo, erisipela ambulante, escápula flotante, marcha de gallo, neumonía migrante...;

- gesto, mímica: boca de carpa, danza de San Antonio, labio de tapir...;

- cadencia: pulso acoplado / convulsivo / febril / funicular / ondulante / vibrante, respiración bostezante, respiración sincopal...;

- consistencia: bronquitis plástica, vesícula en porcelana, vientre en madera I en gelatina...; 
- sonido: sonido de campana, chapoteo, estertor en cloqueo de gallina, murmullo respiratorio, respiración tubárica, soplo metálico, voz de pecho, voz de falsete...;

- características adicionales vinculadas con conocimientos de índole social, histórica, mitológica o literaria: labio de Habsburgo, safismo, cesárea, agripa...;

- características de segunda orden (los virtuemas se presentan como especialmente importantes para la constitución de la analogía): dolor fantasma, embarazo fantasma, ensalada de palabras...

\section{Análisis semántico-funcional}

Como hemos podido comprobar, un número considerable de las denominaciones reunidas en nuestra tipología toman como campo de partida objetos o entidades físicas, cuya forma o función parece relativamente fácil de determinar. Parece sintomático que en el caso de la terminología médica las formas de las entidades topográficas $\mathrm{o}$ arquitecturales fundamenten toda una red metafórica que remite a los órganos o partes del cuerpo (acueducto, atrio, bóveda, pared, pilar, túnel...). El hecho de recurrir de modo tan sistemático a las analogías que se basan en el parecido de forma puede explicarse seguramente por la necesidad de visualización que durante siglos caracterizaba el ámbito médico. Como señala acertadamente Kacprzak (1997: 152), durante siglos los cinco sentidos del médico constituían la base del diagnóstico; los nombres que reflejaban similitudes de forma facilitaban, además, la memorización y el proceso de aprendizaje.

La selección sémica que selleva a cabo en el caso de la terminologización de índole metafórica conduce a la elección de los elementos de significado que no resultan incompatibles con la nueva realidad representada. La selección de tales características opera dentro de todo el subsistema de semas, de ahí que no puedan desatenderse ni semas específicos (semantemas), ni genéricos (clasemas), ni tampoco los denominados semas virtuales o connotativos (Baran, 2003: 150). En varias ocasiones, las metáforas terminológicas encuentran su fundamento en transposiciones metafóricas propias de la lengua general. No olvidemos, no obstante, que aparte de valores denotativos o connotativos fácilmente identificables, podemos encontrarnos a menudo ante usos en cuya decodificación el 
conocimiento de la llamada carga cultural compartida ${ }^{6}$ no es suficiente. Tal puede ser el caso de los términos cromáticos utilizados en la terminología médica. Al considerar, por ejemplo, los términos como asfixia azul y asfixia blanca, rápidamente nos daremos cuenta de que los nombres de colores, además de asumir una función descriptiva, adquieren en terminología una función distintiva (en el caso de los términos citados, no se designa en primer lugar un color, sino que se pone el acento en los distintos síntomas de la disfunción [en la asfixia azul, la circulación continua, mientras que la asfixia blanca lleva a la gradual abolición de los reflejos]).

El proceso de denominación propio del ámbito de la medicina no debe limitarse únicamente al mecanismo de abstracción sémica. No cabe duda de que los planteamientos de índole cognoscitiva permiten agrupar las lexicalizaciones terminológicas de carácter metafórico en campos conceptuales. La percepción del espacio, junto con la percepción visual y la experiencia en la manipulación de objetos, pueden conducir a la delimitación de distintos marcos o esquemas integrativos. Parece sintomático que la terminología médica, y en especial su rama referida a la anatomía, desarrollen sistemáticamente dos campos que podrían definirse, respectivamente, como «el cuerpo humano es un EDIFICIO» \{arcada, bóveda, cámara, cripta, fosa, laberinto, pabellón, pared, pilar, pirámide, puerta de entrada, suelo, tejido, túnel, vestíbulo...\} y «el cuerpo humano es una REALIDAD GEOGRÁFICA» \{golfo, islotes, lago, laguna, meseta, monte, región...\}. Otro rasgo sería una actualización relativamente frecuente de elementos que se refieren a «lo humano». No se trata, sin embargo, de una direccionalidad interna fácil de adivinar («realidades orgánicas del hombre como fuente de términos médicos»), sino que en varias ocasiones quedan actualizados los rasgos de índole más abstracta o incluso psicológica (considérense los términos como célula indiferente, diabetes frustrada, microrganismo oportunista, músculo antagonista, rabia furiosa...).

Dentro de los términos recopilados destaca también la categoría de epónimos ${ }^{7}$. Se trata, de hecho, de tecnicismos onomásticos que derivan en gran parte de los nombres de los personajes históricos que padecieron

${ }^{6}$ La versión castellana de la noción propuesta por Galisson (1987): charge culturelle partagée.

7 Se supone que los epónimos, tan frecuentes en la terminología médica, deberían contribuir a la universalización del lenguaje científico. En realidad, su uso raras veces facilita realmente la comunicación internacional. Es así porque muchos de los epónimos varían de una lengua a otra; no faltan ocasiones en las que los epónimos carecen de valor descriptivo y apenas ofrecen información acerca del término en cuestión. Algunos investigadores consideran incluso que estamos ante una clase denominativa especialmente agravante para la memoria. 
ciertos procesos patológicos o de los personajes mitológicos, cuyas cualidades o personificaciones están relacionadas con las patologías que designan. Así, con alejandrismo (de Alejando Magno) nos referimos a la manía de conquista o creencia patológica de ser un gran conquistador; cresomanía (de Creso, rey de Lidia) indica el delirio en el que el paciente se cree en posesión de grandes riquezas; priapitis (de Príapo, dios campestre) designa la inflamación del pene; sífilis (de Siphylo, personaje del poema de Girolamo Fracastoro de Verona) es la conocidísima enfermedad venérea. Entre otros epónimos se hallan, igualmente, distintas denominaciones humorísticas o ludónimos (catalinas [sífilis], feliciano [cópula carnal]) (García Gallarín, 1997: 169).

El análisis de los términos metafóricos de procedencia metafórica permite acercarse, de igual modo, al interesantísimo problema de lo que podríamos denominar concurrencia sinonímica ${ }^{8}$. En el caso de la terminología médica no resulta nada difícil detectar series de dobletes formados por términos con base metafórica (teñidos, en ocasiones, de matizaciones expresivas) y denominaciones de origen grecolatino (muy a menudo mucho menos transparentes para el público no especializado). Como ejemplos podrían citarse los siguientes pares:

corazón atlético / hipertrofia del corazón

cráneo en torre / turricefalia

enfermedad danzante / tarantismo

degeneración vitrea / necrosis de coagulación

mal americano / neurastenia

nariz en martillo / rinofima

ruido de tictac / embriocardia

sutura de peletero / soltura continua simple

Sin lugar a dudas, los dobletes terminológicos ofrecen valores pragmáticos diferentes, siendo las denominaciones metafóricas más evocadoras que los términos cultos grecolatinos (obviamente, estos últimos pueden contar con una motivación metafórica; su legibilidad es, sin embargo, de grado distinto). Es de suponer que la interpretación de cada elemento que forma parte del doblete se fundamenta en el establecimiento de variantes de índole comunicativa. El empleo de los términos motivados metafóricamente parece predominar entre los no iniciados o es propio del ámbito iniciado/no iniciado (médico-paciente). No olvidemos, no obstante, que en el caso de la terminología médica,

8 Aunque Wüster, considerado como padre de la terminología moderna, condenaba la sinonimia, pretendiendo eliminarla del campo terminológico, hoy nadie niega su existencia en este ámbito. Obviamente, raras veces estamos ante sinonimia absoluta, ya que en la gran mayoría de casos se perfilan diferencias a nivel de uso. 
los elementos referentes a lo que es signum social, cohesión, economía o especialización, se combinan a menudo con la supuesta función críptica (la cual se manifiesta, en menor o mayor grado, en cada lenguaje de especialidad). El lenguaje médico junto con sus términos permite la transmisión de informaciones "filtradas", lo cual equivale al deseo de ocultar determinadas realidades a través de unidades terminológicas especialmente escogidas. En la comunicación médico-enfermo, aparentemente en contra del principio pragmático de modo, suele utilizarse a menudo términos de base culta, todo aquello con el propósito de ocultar realidades especialmente dolorosas para el paciente (Baran, 2003: 184). Las formas metafóricas, integradas, por supuesto, dentro del sistema terminológico, en ocasiones pueden resultar excesivamente directas (efectivamente por su alto grado de transparencia). Así pues, las denominaciones cultas tipo hepatoptosis o actinomicosis lingual adquieren un valor cercano al eufemístico.

\section{A modo de conclusión}

Las transposiciones de índole metafórica propias del ámbito terminológico de la medicina, como otras metáforas terminológicas, corresponden a un patrón de lexicalización que difiere del esquema de lexicalización que caracteriza la lengua general. La frecuencia de uso junto con la progresiva pérdida de la percepción del carácter metafórico no son factores suficientes para considerar una determinada lexía del lenguaje médico como una formación terminológica lexicalizada: la inserción en el marco de un diccionario o glosario terminológico que, por su parte, somete una unidad al control de una definición especializada, se presenta como un criterio especialmente relevante. Las metáforas terminológicas, entre ellas las del ámbito de la medicina, no son, por tanto, creaciones de uso ocasional o accidental que caracterizan, por ejemplo, el discurso divulgativo.

Las metáforas terminológicas que se registran en el campo de la medicina parecen constituir una modalidad conceptual-denominativa interesante, que, aparte de desempeñar determinadas funciones referenciales, remite a unos peculiares valores de índole pragmática. Es también de suponer que tanto el nivel conceptual como el pragmático coexisten en una estrecha relación: como hemos podido observar, el hecho de recurrir a la metáfora terminológica puede ser ocasionado por una búsqueda explícita de los valores que derivan de la fase de 
conceptualización. En medicina, las transposiciones de tipo metafórico desempeñan también una función mnemónica: se trata, de hecho, de las unidades que en numerosísimas ocasiones permiten denominar de manera cómoda un fenómeno o una noción, facilitando así su memorización. En un número considerable de casos, las metáforas terminológicas asumen también una función descriptiva y distintiva. Seguramente, las imágenes que se escondían detrás de los términos de origen metafórico constituían frecuentemente comparaciones acertadas, particularmente útiles cuando faltaban métodos modernos de visualización (como la fotografía): denominaciones como factura en caña verde, cara de luna llena, boca de carpa o diarrea en agua de arroz son prueba de ello.

\section{Bibliografía}

BARAN, M. (2002). «La metáfora y la negociación denominativa en terminología», Estudios Hispánicos, X, 69-78.

BARAN, M. (2003). Metáforas cristalizadas en terminologías de lengua española. Łódź / Łask: Oficyna Wydawnicza Leksem.

BURGOS CUADRILLERO, B. y ROHR SCHRADE, K. I. (2016). «Estudio contrastivo de la terminología médica alemán-español mediante los diferentes procesos de formación de palabras (Wortbildung)», en M. F. LITZLER, J. GARCÍA LABORDA y C. TEJEDOR MARTÍNEZ (eds.), Beyond the univers of Languages for Specific Purposes: the 21st century perspective. Alcalá: Servicio de Publicaciones de la Universidad de Alcalá, 77-82.

CABRÉ, M. T. (1993). La terminología. Teoría, metodología, aplicaciones. Barcelona: Editorial Antártida / Empúries.

GALISSON, R. (1987). «Accéder à la culture partagée par l'intermise des mots à C.C.P.», Etudes de Linguistique Appliquée, 67, 119-140.

GARCÍA GALLARÍN, C. y GARCÍA GALLARÍN, C. (1997). Deonomástica hispánica. Vocabulario científico, humanístico y jergal. Madrid: Editorial Complutense.

GUITÉRREZ RODILLA, B. M. (1998). La ciencia empieza en la palabra. Análisis e historia del lenguaje científico. Barcelona: Ediciones Península.

HOLTON, G. (1993). «La imaginación en la ciencia», en L. PRETA (dir.), Imágenes y metáforas de la ciencia. Madrid: Alianza Editorial, 29-57.

KACPRZAK, A. (1997). «La métaphore dans la langue médicale», Studia Romanica Posnaniensia, XXII, 151-157.

KACPRZAK, A. (2000). Terminologie médicale française et polonaise. Analyse formelle et sémantique. Łódź: Wydawnictwo Uniwersytetu Łódzkiego.

KOCOUREK, R. (1994/1995). «Set Metaphors en English Linguistic Terminology», ALFA, 7-8, 361-389. 


\section{Diccionarios}

CLÍNICA UNIVERSIDAD DE NAVARRA (2018). Diccionario médico. Pamplona: Universidad de Navarra [en línea] <https://www.cun.es/diccionario-medico $>$, fecha de consulta: mayo-septiembre de 2018.

CHAMPNEY, B. y SMIDDY F. G. (1987). Sintomas, signos y síndromes: definición y descripción. Barcelona: Doyma.

DURAND, H. y BICHET, P. (1992). Diccionario de enfermedades y elección de exploraciones complementarias. Barcelona: Doyma.

FACULTAD DE MEDICINA DE LA UNIVERSIDAD DE NAVARRA (2000). Diccionario de Medicina. Madrid: Espasa.

REAL ACADEMIA NACIONAL DE MEDICINA (2012). Diccionario de términos médicos. Madrid: Médica Panamericana.

VV. AA. (1992). Diccionario Terminológico de Ciencias Médicas. Barcelona: Masson S. A.

VALDÉS MIYAR, M. (1996). Diccionario de Psiquiatría. Barcelona: Masson S. A. 